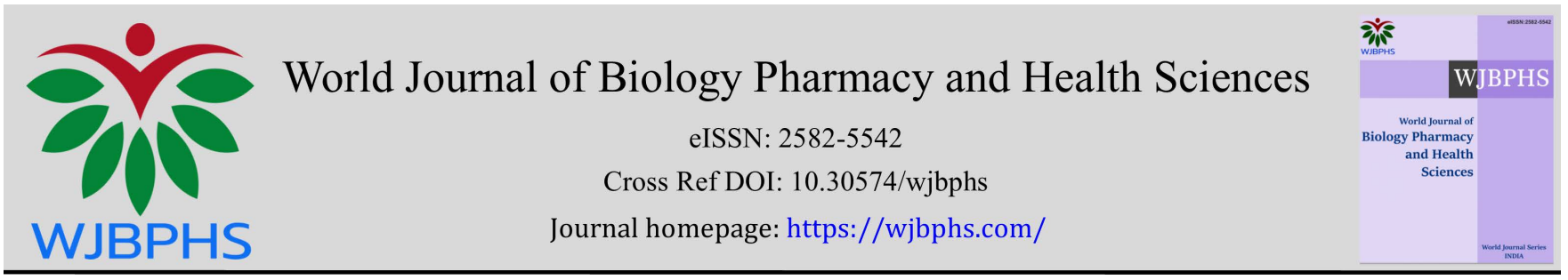

(RESEARCH ARTiCLE)

\title{
Epidemiology of Trichomons vaginalis among pregnant women attending antenatal care in Ipokia Local Government Area of Ogun State, Nigeria
}

\author{
Erube Akuoma Sandra 1, Idowu Emmanuel Taiwo 1, Ibekpobaoku Agartha Nkem 1, Ajayi Morakinyo \\ Bamikole ${ }^{2,}{ }^{*}$, Gogwan Peter lengshat ${ }^{2}$ and Aiyedogbon Adenike Shola ${ }^{2}$ \\ ${ }^{1}$ Department of Zoology, University of Lagos, Lagos, Nigeria. \\ ${ }^{2}$ Microbiology Department, Nigerian Institute of Medical Research, Yaba, Lagos, Nigeria.
}

World Journal of Biology Pharmacy and Health Sciences, 2021, 05(02), 012-018

Publication history: Received on 09 January 2021; revised on 29 January 2021; accepted on 02 Februay 2021

Article DOI: https://doi.org/10.30574/wjbphs.2021.5.2.0007

\begin{abstract}
The study assessed the epidemiology of Trichomonas vaginalis among 200 pregnant women aged between 15-45 years attending antenatal care in three private hospitals in Idiroko, Ipokia Local Government Area of Ogun State, Nigeria.

Direct wet mount microscopy and culture were used on High Vaginal swabs collected from the consented participants after the administration of questionnaire to collect their knowledge, attitude and practice (KAP) with regard to the Trichomoniasis.

The educational profile showed that $23 \%$ had primary education while $60 \%$ had secondary education. Age group between 15-25years 174(67\%) of the participants were traders. 30(15\%) Prevalence were positive for Trichomonas from wet mount microscopy method while no positive was recorded in the cultures. There was a statistical difference between number of sexual partners, occupation, family type and previous sexually transmitted infection. 114(57\%) of respondents have not heard of sexually transmitted disease while $173(86 \%)$ of respondents were not aware that Trichomoniasis is a sexually transmitted disease.
\end{abstract}

The result from this study indicate that trichomoniasis is still a public health problem in Nigeria and little have been done for its control. The risk factors of this disease includes age group, number of sexual partners, trimester and occupation.

Keywords: Trichomonas vaginalis; pregnant women; Ipokia Local Government; Ogun State

\section{Introduction}

Trichomonas vaginalis is an ovoid parasitic protozoan, which causes trichomoniasis in humans. The parasite lives in the female lower genital tract (vulva, vagina, or urethra), including the male urethra and prostate, where they replicate asexually by binary fission. Trichomoniasis is the most curable Sexually Transmitted Infection (STI) with a worldwide annual prevalence range of 170-180 million. It affects an estimate of 248 million people worldwide and about $40 \%$ of these people are in the African region [1].

Based on wet mount microscopy sensitivity, the World Health Organization estimated that the global prevalence, ranges from $60-80 \%$ [2] while an estimated 42.8 million are in African region [3]. Trichomonas vaginalis is the most common Sexually Transmitted parasitic Disease (STPDs) in Nigeria; and studies on STPDs remain relatively scanty [4].

\footnotetext{
${ }^{*}$ Corresponding author: Ajayi Morakinyo Bamikole

Microbiology Department, Nigerian Institute of Medical Research, Yaba, Lagos, Nigeria.
}

Copyright (C) 2021 Author(s) retain the copyright of this article. This article is published under the terms of the Creative Commons Attribution Liscense 4.0. 
This infection ranks third after bacterial vaginosis and candidiasis among the diseases that commonly progress to vaginal symptoms [5]. Infection with Sexually Transmitted Parasitic Diseases (STPDs) has resulted in debilitation or anatomic deformities that make sex impossible as a result of direct damage to the male and female reproductive organs including impairing fertility via the inhibition of gamete production [6].

Factors such as poor personal hygiene, sexual recklessness, multiple sex partners, low socio-economic status, increase in poverty and underdevelopment are associated with high incidence of infection $[7,8]$. However, $\mathrm{T}$ vaginalis is rarely transmitted through contaminated specula or toilet seats because the parasite dies quickly in a dry environment [9].

A vaginal pH level < 4.6 has been identified as a risk factor for trichomoniasis , but Brotman et al., 2012 [10] revealed that $90 \%$ of women with trichomoniasis have a $\mathrm{pH}$ level $>4.5$, which is a criterion for diagnosing Bacterial vaginosis, $\mathrm{T}$. vaginalis infection or both. Women with trichomoniasis may notice a characteristic frothy greenish vaginal discharge; itching, burning, painful urination and may have small punctuated haemorrhagic spots on the vaginal and cervical mucosa. Symptoms are cyclic and worsen around the time of menses [11]. Trichomoniasis predisposes women to HIV, Pelvic Inflammatory Disease (PID), cervical cancer, and other sexually transmitted diseases including Chlamydia and Gonorrhea [12]. Pregnant women infected with T. vaginalis are at risk for adverse pregnancy outcomes which may include premature rupture of membranes, premature labor and post-abortion infections [13].

Available data shows that prevalence of trichomoniasis range from about $0 \%$ to as high as 58\% in Nigeria [14,15]. A research study carried out by Anosike et al., 1993 [16] shows 37\% prevalence among females in a higher institution in Aba, Nigeria.

Trichomoniasis is the most curable sexually transmitted infection worldwide. There is still high prevalence in Nigeria and this made it a compelling public health concern due to its contribution to poor health outcome especially to neonates. Despite the availability of drugs, trichomoniasis is relatively neglected compared to other sexually transmitted diseases. This study was therefore designed to ascertain the epidemiology of Trichomonas vaginalis among the study population as they relate to such to the risk factors that may predispose a population to the disease, and to compare the sensitivity of wet mount microscopy with culture technique in the diagnosis of trichomoniasis which will help to create awareness among participants and promote a healthy sexual life.

\section{Material and methods}

\subsection{Study Area}

The study was conducted in Idiroko, Ipokia Local Government Area of Ogun State using three major private hospitals which Includes: Mayowa Clinic and Maternity; Remi Clinic and Maternity; Ire-Ayo Maternity.

Ipokia L.G.A has a coordinate of $6032 ` \mathrm{~N} 20$ 51`E with a land mark of $629 \mathrm{~km} 2$ (243sq mi) and a total population of 150,426 according to 2006 census. This is a typical rural-urban settings lacking in basic amenities like good roads, electricity and poor housing made of mud with inhabitants facing poor sanitation, lack of proper drainage channels and erosion. The dominant ethnic group is Yoruba. Islam and Christianity are the common religious group.

\subsection{Study Design}

This was a cross-sectional descriptive study. A total of 200 consented pregnant women attending antenatal care within the ages of 15-45years were selected for the study. The sample size was computed with a $20 \%$ prevalence of Trichomonas vaginalis based on research conducted in Ogun State and a precision of $0.05 \%$ at $95 \%$ confidence interval [17].

\subsection{Sample Collection}

Two samples were collected from each consented pregnant woman to determine the Trichomonas vaginalis status of the individual using sterile disposable vaginal swab stick and speculum. Each sample collected was coded to matche the individual survey number on the questionnaire. Two sterile cotton tipped swab sticks, one after the other were inserted at least $2.5 \mathrm{~cm}$ (1 in.) with a sterile speculum into the vagina of each pregnant woman by a clinician to collect vaginal discharge. 


\subsection{Laboratory Analysis}

The HVS samples were analyzed at the point of collection in the various hospitals while samples for cultures were taken to the Parasitology Unit of Microbiology Department of Nigerian Institute of Medical Research (NIMR) at Yaba, Lagos, Nigeria.

\subsection{Parasitological Examinations}

All HVS samples were examined by wet microscopy at the point of collection with the assistant of laboratory technicians after collection. A drop of the vaginal exudates was mixed with a drop of normal saline and emulsified exudates was placed on a clean grease-free slide, cover slip was gently placed. The preparation was examined for motile flagellates under the microscope using $\mathrm{x} 10$ and $\mathrm{x} 40$ objective lenses.

\subsection{Culture Examination}

The swabs with the vaginal discharge were removed from the Stuart's transport media and used for inoculation.

Culture were placed into Trichomonas Medium (Oxoid) enriched with sterile bovine serum. Both microscopically trichomonads negative and positive high vaginal swabs samples were cultured in labeled sterile bijou bottles. The cultures were incubated at 360C. Afterwards, the smears obtained from the culture were examined microscopically each day for 7 days at 24 hours interval for the presence of T. vaginalis and were discarded as negative on the seventh day.

\subsection{Ethical Consideration}

Ethical approval was obtained from the Institutional Review Board of Nigerian Institute of Medical Research, Yaba. Lagos, Nigeria. Written and verbal consent was obtained from the participating hospitals and pregnant women before the study commenced. Questionnaires were assigned unique codes and the result of each participant's questionnaire and test were kept in confidence.

\subsection{Data Analysis}

Data analysis was done using Microsoft Excel 2010 and Statistical Package for Social Science (SPSS), version 23.0, calculated $\mathrm{p}$-values were considered to be statistically significant with $\mathrm{p}<0.05$ using Chi-square test

\section{Results}

Out of the 200 pregnant ante-natal women examined in the three health facilities namely; Ireti-Ayo Maternity, Mayowa Maternity and Clinic and Remi Clinic, 30(15\%) were positive for wet mount examination at the point of collection while $170(85 \%)$ were negative no positive result was observed for the cultural method .Fig 1

Table 1 shows the Prevalence of T. vaginalis in the surveyed hospitals in Ipokia Local Government Area of Ogun State, Ireti-Ayo Maternity had the highest prevalence of 18(16.7\%) and Remi- Clinic with the lowest prevalence of 2(6.7\%).

Table 2 showed the study population comprising age group between 15-45years. The highest percentage prevalence was recorded among age group 15-25years (63\%) and the lowest from 37years and above (10\%).

The Socio-demographic characteristics of respondents in Table 2 also discovered that participants with secondary educational status had the highest prevalence of the infection (60\%) and those with tertiary having the lowest (17\%). The occupation with highest prevalence are traders $(67 \%)$ while Islamic religion had the highest numbers of positive cases $(63 \%)$.

Table 3 shows the Risk factors associated with trichomonaisis in pregnant women that participated in the study. These includes. 


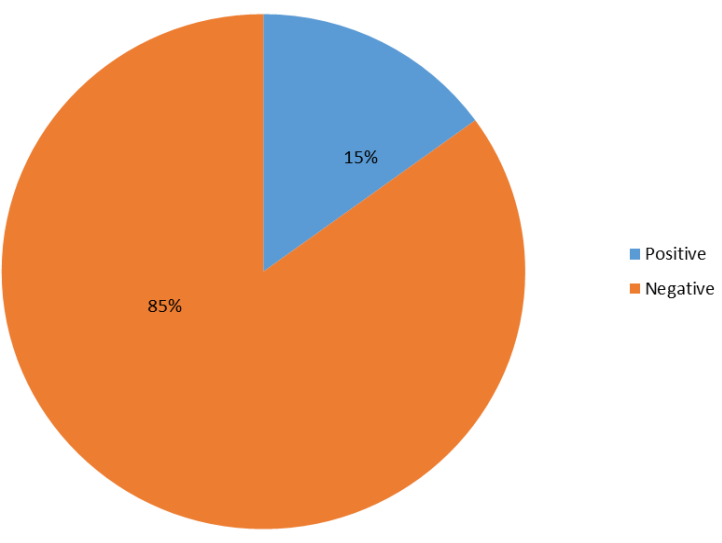

Figure 1 Prevalence of T. vaginalis in Ipokia Local Government Area of Ogun State.

Table 1 Prevalence of T. vaginalis in the surveyed hospitals Ipokia Local Government Area of Ogun State

\begin{tabular}{|l|l|l|l|}
\hline Hospitals & No. examined & No. Positive & Prevalence \% \\
\hline Mayowa & 62 & 10 & 16.1 \\
\hline Ireti-Ayo & 108 & 18 & 16.7 \\
\hline Remiclinic & 30 & 2 & 6.7 \\
\hline
\end{tabular}

Table 2 Socio-demographic characteristics of respondents.

\begin{tabular}{|l|l|l|}
\hline Variable & No. examined & Percentage (\%) \\
\hline Age group & & \\
15-25years & 108 & 63 \\
26-35years & 72 & 27 \\
37 and above & 20 & 10 \\
\hline Educational status & & \\
Primary & 57 & 23 \\
Secondary & 128 & 60 \\
Tertiary & 15 & 17 \\
\hline Religion & & \\
Christianity & 99 & 37 \\
Islam & 101 & 63 \\
\hline Occupation & & \\
Civil servant & 22 & 27 \\
Student & 4 & 6 \\
Trader & 174 & 67 \\
\hline Family type & 106 & 80 \\
Monogamous & 94 & 20 \\
Polygamous & & \\
\hline
\end{tabular}


Table 3 Risk factors of trichomonaisis among pregnant women in Ipokia, Local Government Area

\begin{tabular}{|l|l|l|l|l|}
\hline \multicolumn{2}{|l|}{ Variables } & Number examined & Number infected (\%) & P value \\
\hline \multirow{3}{*}{ Number of sex partners } & One & 190 & $25(13.2)$ & \multirow{2}{*}{0.001} \\
\cline { 2 - 4 } & More than 1 Partner & 10 & $5(50)$ & \\
\hline \multirow{2}{*}{ Trimester } & $1^{\text {st }}$ & 36 & $16(44.4)$ & \multirow{2}{*}{0.000} \\
\cline { 2 - 4 } & $2^{\text {nd }}$ & 93 & $9(9.7)$ & \\
\cline { 2 - 4 } & $3^{\text {rd }}$ & 71 & $5(7)$ & \multirow{2}{*}{0.005} \\
\hline Family type & Monogamous & 106 & $24(22.6)$ & \\
\cline { 2 - 4 } & Polygamous & 94 & $14(6.4)$ & \multirow{2}{*}{0.47} \\
\hline \multirow{2}{*}{ Previous STI infections } & Yes & 108 & $16(17.4)$ & \\
\cline { 2 - 4 } & No & 92 & & \\
\hline
\end{tabular}

\section{Discussion}

Trichomoniasis is an unpleasant parasitic infection that can go undiagnosed for years and is mainly transmitted by asymptomatic carriers. These asymptomatic carries may develop symptoms like vaginitis, cervicitis, urethritis and adverse birth consequences in pregnant women as time progresses $[18,19,5]$. Disease prevalence is variable and diagnoses are often difficult due to the nature of the organism and the noncompliance of subject to either accept the presence of the symptoms or to submit themselves for screening probably for personal reasons.

The result of this study has demonstrated the prevalence of Trichomonas vaginalis among pregnant women attending ante-natal in Idiroko, Ipokia L.G.A, Ogun State. T. vaginalis was found in 30(15.0\%) of the pregnant women examined in the study (Table 2). The prevalence rate obtained is the same with the findings of $[20,21]$ in Benin City. The prevalence is high compared to the findings of Ogomaka et al., 2018 in Orlu, Imo state [22, 23] among women of reproductive age in rural community in Nigeria and Alexander et al. in 2018 [24] in Lagos State reported a lower than that of Ojurongbe et al., 2010 [17], who recorded 20\% prevalence among pregnant women in Abeokuta.

Ochei et al., 2014 [25] in his study recorded 0\% in all participants in a study carried out in some part of Edo State arguing that the $0 \%$ prevalence may be as a result of intense study or active control program in the study area.

This study observed that higher prevalence was recorded in one of the hospitals (Ire-Ayo) which double as a maternity. Participants who attended the maternity were low income earners and the uneducated. This study indicated that all samples diagnosed by culture were negative which may be as a result of delay in diagnosis and transportation to the laboratory.

Meanwhile, the study shows the highest prevalence with respect to age group to be among the age range of 15-45years $108(63 \%)$, which was followed by the age range 26-35years with $72(27 \%)$. This prevalence is in dissimilarity from the research of Etuketu et al., 2018 who recorded the highest prevalence among age group 40-44years. According to Krieger 1995 and Sena 2007, [26, 27] the disease occurrence correlated with the level of sexual activity of the group of people within those age bracket.

Also, the evidence for sexual transmission of T. vaginalis is very strong as prevalence is highest among participants with increased sexual activities and multiple sex partners. The reasons for this increase in infection among age range of 1525years may be due to their inability to stick to their sexual partners and having no control of their sexual urge.

Educational attainment related prevalence showed that prevalence was highest among those that had secondary education $128(60 \%)$ while the least prevalence was observed among tertiary participants $20(10 \%)$ which supports the statement by Soper, 2004 [19] that low educational status is associated with T. vaginalis infection.

Occupational related prevalence showed highest infection among traders with $10.0 \%$ (Table 2). The high prevalence rate of infection amongst traders agrees with the findings of Sam-wobo et al., 2012 [27] which might be associated with 
sexual activeness as well as exposure to factors such as poor sanitary facilities, shared usage of toiletries that are characteristic of most trading centers in Idiroko. This high prevalence may be implicative on health challenges to unborn babies and also in amplifying transmission of other sexually transmitted infections.

Prevalence of trichomoniasis decreased with the term of pregnancy. Hence, prevalence was highest in the first trimester $16(44.4 \%)$ and lowest in the third trimester 5(7\%) (Table 4). This is in agreement with the works of Umeaku et al., 2019 and Akinbo et al., 2017 [28,29] but in disagreement with Ibekpobaoku et al., 2017 [13] who recorded that there was no infection among women in their first trimester. The study observed that number of sex partners, term of pregnancy, occupation and family type were statistically significant to infection at $\mathrm{P}<0.05$.

\section{Conclusion}

Conclusively, there was a significant difference between the numbers of sexual partners and the prevalence of Trichomonas vaginalis. This is a hospital based study and may not be a representative of the general population of the study area, a more comprehensive study that will take care of the entire population is hereby recommended.

\section{Compliance with ethical standards}

\section{Disclosure of conflict of interest}

All authors declare that they have no conflict of interest.

\section{Statement of informed consent}

Informed consent was obtained from all individual participants included in the study.

\section{References}

[1] World Health Organization. Prevalence and Incidence of selected sexually transmitted infections, Chlamydia trachomatis, Neissera gonorrhoeae,Syphilis and Trichomonas vaginalis: Methods and results used by WHO to generate 2005 estimate. WHO library cataloguing-in-publication. 2011; 20-21.

[2] Van Der Pol B. Trichomonas vaginalis infection: the most prevalent non-viral sexually transmitted infection received the least public health attention. Clin. Infect. Dis. 2007; 44(1): 23-25.

[3] World Health Organization DoRHaR. Global incidence and prevalence of selected curable sexually transmitted infections - 2008. Report No. 2012.

[4] Amadi ANC Nwagbo AK. Trichomonas vaginalis infection among women in Ikwuano, Abia State, Nigeria. J Appl Sci Env Manag. 2013; 17: 389-393.

[5] McClelland RS, Samgare T, Hessan MH, Lavreys L, Madaliya K et al. Infection with Trichomonas vaginalis increases the risk of HIV- 1 acquisition. Journal of infectious diseases. 2007; 195: 698-702.

[6] Okafor CF, Omudu AE. Parasitic diseases and sexual disability: A critical review of some parasitic diseases with serious repercussions. Anim Res Int. 2005; 2: 255-260.

[7] Woken GN. Trichomonas vaginalis infection in some parts of Niger Delta Region, River State Nigeria. Journal of Parasitology. 2006; 27: 68-72.

[8] Ulogu 0, kejindu IM. Prevalence of Trichomoniasis among women in Nnewi, Anambra State Nigeria, Nigerian Journal of Parasitology. 2007; 28: 24-30.

[9] Ukoli,FMA. Introduction to Parasitology in Tropical Africa.1st Edition, Textflow Limited, Nigeria. 1990; $390-395$.

[10] Brotman RM, Bradford L, Conrad M. Association between Trichomonas vaginalis and vaginal bacterial community composition among reproductive-age women. Sex Trans Dis. 2012; 39(10): 807- 812.

[11] Petrin D, Delgaty K, Bhatt R, Garber G. Clinical and Microbiological Aspects of Trichomonas vaginalis. Clinical Microbiology Reviews. 1998; 11(2): 300-317.

[12] Cherpes TL, Wiesenfeld HC, Melan MA, Kant JA, Cosentino LA, Meyn LA, Hillier SL. The associations between pelvic inflammatory disease, Trichomonas vaginalis infection, and positive herpes simplex virus type 2 serology. Sexually Transmitted Diseases. 2006; 33: 747. 
[13] Ibekpobaoku AN, Idowu ET, Otubanjo OA, Ajayi MB, Onyekwele AN, Anusu AO. Trichomonaisis in pregnant women attending four primary health centers in selected Local Government areas in Lagos State, Nigeria. Nigerian Journal of pure and applied science. 2018; 28-36.

[14] Mairiga A, Balla H, Ahmad M. Prevalence of Trichomonas vaginalis infections among antenatal clients in Maiduguri Nigeria. International Journal of Biological and Medical Research. 2011; 2: 998-1002.

[15] Omorodion Oriri Asemota. Trichomoniasis in Nigeria: a review. Industrial Safety and Environmental Technology Department, Petroleum Training Institute, Effurun, Nigeria. Biomed Res. 24 April 2018; 29(12): 2532-2539.

[16] Anosike JC, Onwuliri CO, Inyang RE. Trichomoniasis amongst students of a higher Institution in Nigeria. Applied Parasitology. 1993; 34(1): 19-25. 